\title{
Naturales, vecinos y extranjeros en el ejercicio de cargos públicos y oficios. Buenos Aires (ciudad y campaña), 1812-1815
}

por

Fabricio Gabriel Salvatto ${ }^{1}$ y Guillermo Banzato ${ }^{2}$

Universidad Nacional de La Plata-CONICET

En este artículo nos proponemos analizar la situación jurídica y politica de los extranjeros que ocupaban cargos públicos y ejercian oficios en el Río de la Plata entre 1812 y 1815 , a partir de documentos originales de la época. Demostramos que los derechos del natural y de vecino fueron los principales ejes sobre los que se continuaron planteando las prácticas políticas. En Buenos Aires, las cartas de ciudadanía se otorgaban discrecionalmente según lo resuelto por las autoridades y de acuerdo con las necesidades de la revolución.

PALABRAS ClaVE: oficios; cargos públicos; ciudadanía; revolución de mayo.

Cómo Citar este artículo / Citation: Salvatto, Fabricio Gabriel y Banzato, Guillermo, "Naturales, vecinos y extranjeros en el ejercicio de cargos públicos y oficios. Buenos Aires (ciudad y campaña), 1812-1815", Revista de Indias, LXXVII/269 (Madrid, 2017): 169-195, doi:10.3989/revindias.2017.006.

\section{INTRODUCCIÓN ${ }^{3}$}

En las últimas décadas los estudios sobre la ciudadanía política desde la Revolución de Mayo hasta el recrudecimiento de la guerra de independencia

1 fsalvatto@fahce.unlp.edu.ar ORCID iD: http://orcid.org/0000-0002-0055-2556.

2 gbanzato@fahce.unlp.edu.ar ORCID iD: http://orcid.org/0000-0003-3250-8768.

3 Una primera versión de este artículo fue presentada en las "VII Jornadas de Historia y Cultura de América, II Congreso Internacional y II Encuentro de Jóvenes Americanistas. La construcción de las independencias: documentos, actores y representaciones". Universidad de Montevideo (Uruguay), 25 y 26 de Julio de 2013. Agradecemos los comentarios de Francisco Javier González Errázuriz, María Inés Carzolio, Fernando Barba y los evaluadores de la revista. 
se detuvieron especialmente en la relación y diferenciación entre las condiciones del vecino y del ciudadano ${ }^{4}$. La definición de la ciudadanía en el Río de la Plata significó para las autoridades constituidas desde 1810 -y para las de la época preconstitucional- uno de los desafíos más importantes. Por medio de ella no sólo se determinaba quiénes estaban en capacidad de acceder a derechos y obligaciones que debían ser ratificados por el cambio de régimen, sino también se precisaba quiénes podían ser los titulares legítimos en remplazo de las autoridades coloniales ${ }^{5}$.

En este artículo nos proponemos analizar la situación jurídica y política de los sujetos que en su condición de españoles americanos (vecinos-naturales) y de españoles europeos (extranjeros) ${ }^{6}$, disputaron la permanencia en los cargos públicos o en el desempeño de oficios civiles en el Río de la Plata. En este sentido haremos hincapié en los derechos del natural y de vecino como los principales ejes sobre los que se continuaron planteando las prácticas jurídico-políticas luego de 1811. Consideramos que la elección de los casos presentados nos permite ampliar el problema más allá de la cuestión de la vecindad para comprender cómo se instituyen la inclusión y la exclusión de derechos civiles y políticos. Sostenemos que la inclusión de la noción de naturaleza -conocida en el ámbito peninsular y americano- nos permite en este estudio una mejor comprensión de los conflictos surgidos en el contexto revolucionario previo a la declaración de independencia. Entonces, la posibilidad de continuar en el ejercicio de un cargo en la estructura administrativa en la ciudad de Buenos Aires o desarrollar ciertos oficios en los pueblos de la campaña, dependía de los criterios de las débiles y cambiantes instituciones de gobierno para definir quién era un ciudadano; vale decir, quiénes por su condición (nacimiento, residencia, reconocimiento) eran ciudadanos y quiénes obtenían la carta de ciudadanía por determinación de las autoridades porteñas, cómo - por esta razón- se equiparaban sus derechos con los de los vecinos y naturales, y cómo reaccionaban éstos frente a tal situación. Se estudiarán dos casos en los cuales se presentaron situaciones análogas para los que no eran reconocidos como pertenecientes a la comunidad política, es decir para los extranjeros. Análisis que nos permite definir cómo los contemporáneos pensaban la inclusión dentro de la comunidad política que emergía del proceso revolucionario.

4 Cansanello, 2003: 15. Chiaramonte, 1999: 97.

5 Cansanello, 2003: 14-15.

6 Sobre la precisión en la denominación de la época seguimos a Garavaglia (2009), quien ha demostrado que el vocablo «criollo» tenía otra connotación en la época, pues la distinción se hacía entre «europeos» $\mathrm{y}$ «americanos». 
En los clásicos trabajos de la Academia Nacional de la Historia se señaló la tensión que se produjo entre los revolucionarios y los nacidos en España desde el principio de la Revolución de Mayo de 1810. En plena discusión sobre la ampliación de la junta formada en Buenos Aires y a instancias del secretario Mariano Moreno, quien lideraba el ala más radicalizada del movimiento revolucionario, se dictó el decreto del 3 diciembre de 1810 por el cual sólo se nombrarían para cargos civiles, militares o eclesiásticos a los nacidos en el territorio. Aunque el mismo decreto aclaraba que los empleados europeos continuarían en sus funciones sujetos a «su buena conducta, amor al país y adhesión al gobierno» y fomentaba la radicación de extranjeros, le granjeó al secretario la oposición de los españoles. A la derrota política del grupo morenista con la incorporación de los diputados de las provincias del interior formando la Junta Grande, continuó la revocación del decreto hacia fines de diciembre de 18107. En los meses siguientes el grupo triunfante aceptó las peticiones de la gente de los barrios, levantadas por los alcaldes con el acuerdo de los comandantes de milicias en apoyo de Cornelio Saavedra, el presidente de la Junta. La larga lista incluía, en primer término, la de que se expulsara a los españoles europeos, en cuarto lugar se proponía la aplicación de un impuesto sobre las rentas de los bienes de los expulsados ${ }^{8}$. La resolución de la cuestión acerca de la continuidad o revocación de los cargos de los peninsulares se volvió más urgente con el avance de los sucesos revolucionarios. En julio de 1812 fue descubierta una conspiración de españoles europeos liderados por Martín de Álzaga, quien fue fusilado9. Seguidamente, se prohibió a los españoles regentear pulperías y se volvió a considerar la propuesta de preeminencia de los «hijos del país» en el desempeño de los cargos públicos. Además, un número importante de españoles que apoyaban al nuevo régimen solicitaron y obtuvieron nueva ciudadanía ${ }^{10}$. La Asamblea General Constituyente apenas empezó sus deliberaciones desde fines de enero de 1813,

7 Levene, 1962a: 290-292 y 300-303.

8 Levene, 1962b: 323-326.

9 Martín de Álzaga llegó a los 12 años a Buenos Aires procedente de Álava (España). Trabajó hasta los 24 años en la casa comercial de Gaspar Santa Coloma, una de las más importantes de la época. Luego se independizó llegando a levantar su propio negocio que se destacó también en la cumbre de la elite comercial porteña. Tuvo una activa participación en las invasiones inglesas de 1806 y 1807, en los convulsionados meses posteriores encabezó el motín del $1 .^{\circ}$ de enero de 1809 contra el virrey Liniers. Encarcelado, se escapó hacia Montevideo y desde allí retornó a Buenos Aires, pero como estaba procesado no pudo participar de los acontecimientos revolucionarios de 1810, aunque sí lo hizo su grupo de allegados. En 1812 fue acusado de organizar un levantamiento, apresado y fusilado (Cutolo, 1968: 144-146).

10 Canter, 1962a: 450-457. 
tomó rápidas medidas sobre la situación laboral y condición política de los españoles europeos: en febrero determinó que sus empleos dependerían de que se les otorgara «título de ciudadanía», en septiembre ordenó que los españoles se trasladaran cuarenta leguas hacia el interior de las costas ${ }^{11}$.

Trabajos posteriores han profundizado las investigaciones acerca de las medidas políticas tomadas sobre peninsulares que servían en cargos de menor jerarquía, por ejemplo, en el ámbito de la justicia. A partir de julio de 1810 los nuevos gobiernos comenzaron a exigir adhesión activa a la revolución y manifestaciones de patriotismo, a causa de lo cual realizaron importantes reemplazos entre los alcaldes de barrio capitulares ${ }^{12}$. También se han analizado las características ocupacionales y las formas de acceder a los cargos judiciales en las que las diferentes instancias de la nueva burocracia intervenían unas sobre otras ${ }^{13}$. En los últimos años, se ha profundizado en el problema de la hostilidad hacia los españoles, determinando que no era privativa del ámbito de gobierno, sino que también se expresaba en otros sectores de la sociedad, sobre todo en el amplio espectro de la plebe urbana y de la campaña ${ }^{14}$. Un documentado análisis sobre la conspiración de Álzaga de julio de 1812, muestra las tensiones en la vida cotidiana y la reacción del gobierno, que irá aumentando las medidas de represión y control de la actividad de los españoles luego de su derrota ${ }^{15}$.

Cartas de ciudadanía y extranjeros en el Río de la Plata (1813-1815)

En el Antiguo Régimen la vecindad se diferenciaba de la naturaleza principalmente porque esta última se caracterizaba por una relación inmediata con el poder real ${ }^{16}$. La demostración documental de la condición de natural no era exigida en el ámbito de la comunidad local, pero podía afectar en determinadas circunstancias. La obtención de la vecindad podía afectar la vida en dichas comunidades, que se reservaban derechos considerados propios. Era el conjunto de los derechos de natural y de los derechos de vecino los que garanti-

11 Canter, 1962b: 143-146.

12 Halperín Donghi, 1972. Galmarini, 1986. Se han descripto las consecuencias de las medidas económicas que adoptaron los gobiernos de la primera década revolucionaria sobre los principales comerciantes españoles (Galmarini, 1984).

13 Candioti, 2012.

14 Di Meglio, 2006. Pérez, 2009. Fradkin y Ratto, 2010. Para una comparación de los casos rioplatense y mexicano véase León Matamoros, 2010.

15 Pérez, 2012.

16 Carzolio, 2002: 656. Herzog, 2006: 31. 
zaban al sujeto súbdito una plena participación en el disfrute de los privilegios de la sociedad corporativa, como la obtención de cargos públicos y eclesiásticos o en el nivel vecinal el disfrute del ejercicio de un oficio, como panadero, zapatero, carnicero, etc.

No se lograba la vecindad simplemente por el nacimiento en el pueblo, villa o ciudad, ya que dependía más del ius sanguinis que del ius soli. En el caso de una residencia prolongada, no era seguro el otorgamiento de la naturaleza o la vecindad, puesto que no se trataba sólo del paso del tiempo como residente sino de que aquél fuese reconocido como tal por el resto de los vecinos. La convivencia aportaba el conocimiento y la adhesión a las costumbres locales, la adquisición de méritos reconocidos de buen vecino mediante la práctica de la ayuda mutua y de conductas lícitas, de la contribución tributaria, de la participación en las formas del culto, en el amor a la "patria» que se evidenciaba en la intención de integrarse en la comunidad local, pero además de la residencia se exigía la constitución de «casa» y «familia» ${ }^{17}$.

La naturaleza era un requisito fundamental para obtener cargos públicos y oficios eclesiásticos ${ }^{18}$. La reserva de oficios jurisdiccionales y de beneficios eclesiásticos a los naturales de cada reino de la Monarquía podía llevar a que quedaran en exclusividad para los vecinos/naturales, y por consiguiente la vecindad confundirse con la naturaleza independientemente de que se tratara de distintos planos de producción ${ }^{19}$.

Ya en el siglo XIX los criterios gaditanos de ciudadanía incluían la vecindad y la naturaleza ${ }^{20}$. Juan Carlos Garavaglia ha señalado que la

... influencia de algunos elementos institucionales surgidos del proceso revolucionario gaditano [...] que no han sido muy trabajada para el caso rioplatense, abre insospechadas vías para entender mejor los primeros procesos eleccionarios en el Río de la Plata independiente y nos muestra de qué modo se van incorporando nuevos estilos de hacer política abrevando en fuentes y experiencias muy diferentes.

Por ejemplo, -dice el autor- el juramento de la Asamblea de 1813 se inspiró en el gaditano de $1810^{21}$.

17 Carzolio, 2002: 659.

18 Herzog, 2006: 36.

19 Salvatto, 2014.

20 Álvarez Alonso, 2000: 150.

21 Garavaglia 2007: 174. Esta semejanza, según Cánter (1962b: 44), había sido analizada por González, 1938. 
Por otra parte las diferencias en ambos lados del Atlántico son bien conocidas. En principio, porque en la Constitución de Cádiz la soberanía radica en la Nación (española) siendo el gobierno de ésta una Monarquía moderada hereditaria (Art. 14) y que la potestad de hacer las leyes residía «en las Cortes con el Rey» (Art. 15), pero en el Río de la Plata, el proceso revolucionario trastocaría sensiblemente la posibilidad de reunirse con otros reinos hispánicos en una federación transatlántica. Para el tema que trataremos a continuación debemos destacar que en España la legitimidad del rey y las cortes ofrecían un plano de continuidad, a pesar de la crisis iniciada en 1808. En cambio, en Buenos Aires las autoridades que se atribuían la representación en nombre de Fernando VII se reservaban la potestad de otorgar cartas de ciudadanía o de expulsar extranjeros.

Desde el comienzo se planteó el problema del reconocimiento de quiénes serían los ciudadanos y por consiguiente, quiénes los extranjeros, y aunque parezca a primera vista sencillo, la actitud frente a los primeros pasos del movimiento revolucionario y las necesidades políticas y técnicas, determinarían el deslinde entre unos y otros.

En febrero de 1812 Bernardo de Monteagudo 22 expresaba que:

Todos los que no tengan derecho a ser ciudadanos deben dividirse en dos clases: extranjeros y simples domiciliados. Aquéllos son los que no han nacido en el territorio de las Provincias Unidas, éstos los originarios de ellas que por su estado civil o accidental están excluidos del rango de ciudadanos.

Consideraba que la definición de ciudadano debía resolverse por la distinción de nacimiento pero, por otra parte, aludiendo a los derechos del Hombre consagrados por la Revolución Francesa, argumentaba que extranjeros y domiciliados «deben ser considerados hombres: su derecho es igual a los oficios de humanidad, aunque no gocen de las distinciones que dispensa la patria a sus hijos predilectos $\rangle^{23}$. Para Monteagudo, el servicio prestado a la patria permitía al extranjero o domiciliado ser acreedor a los derechos de ciudadano. Ahora bien, existían dos problemas relacionados: por un lado, cómo se juz-

22 Bernardo de Monteagudo, hijo de un comerciante español residente en Tucumán, estudió en la Universidad de Chuquisaca, donde trabó relación con el oidor Ussoz y Mossi, por cuya influencia fue nombrado abogado de la Real Audiencia y Defensor de Pobres en lo Civil. Participó tempranamente en el proceso revolucionario en el Alto Perú redactando conocidas proclamas. Se unió al Ejército del Norte y sufrió la cárcel luego de la derrota de la campaña comandada por Castelli. Recuperada la libertad viajó a Buenos Aires destacándose como publicista. En 1812 representó a la provincia de Mendoza en la Asamblea, en la que fue redactor (Cutolo, 1975: 616-620).

23 Monteagudo, 2008: 75. 
gaban y qué criterios se utilizaban para reconocer los servicios prestados; por otro, quiénes tenían la legítima potestad para otorgar o rechazar esta carta.

En 1812 se dio a conocer un «Proyecto de Constitución para las provincias del Río de la Plata, formado por la Comisión Especial» ${ }^{24}$ que no llegó a regir tal como fue pensado en esas circunstancias pero en el que pueden observarse algunas problemáticas que luego se retomaron en los Reglamentos Provisionales que se promulgaron entre 1815 y 1819. En este proyecto se consideraba ciudadanos a «los hombres libres que, nacidos y residentes en el territorio de la República, se hallen inscriptos en el Registro Cívico» (Cap. VI, art. 1). Lo eran también «los extrangeros que después de cinco años de vecindad y residencia no interrumpida en el país, ó que arraigados en él, ó establecidos en el comercio con capital propio, ó ejerciendo alguna útil industria y pagando las contribuciones, se hallen inscriptos en el Registro Cívico» (Cap. VI, art. 2).

En este proyecto de la Comisión Especial, la ciudadanía se podía perder por la naturalización en un país extranjero, por aceptar empleos, pensiones y distinciones de un gobierno extranjero o por residir fuera de la República por más de siete años (Cap. VI, art. 4). La situación de diciembre de 1812 a pocos días de iniciarse las sesiones de la Asamblea del año XIII, mostraba las posiciones más radicales respecto al reconocimiento de la ciudadanía a los españoles europeos como se observa en el artículo 5 (Cap. VI) del proyecto:

En consideración a la conducta hostil que la generalidad de los españoles europeos han observado constantemente contra la libertad de las Provincias Unidas: á que su obstinada resistencia no ha cedido ni con la fuerza del tiempo, ni con la evidencia de la razón, ni con el atractivo poderoso de la sangre, de la amistad y de las fortunas que nos unen al país, se declara que los españoles europeos, no entran al ejercicio de sus derechos de ciudadanos hasta después de un año de haber sido reconocida la República por la España, si no fuese sojuzgada, ó por las demás potencias si lo fuese.

Este duro artículo fue atemperado por el siguiente, por el cual se exceptuaba de esta ley general a los «españoles europeos que por sus servicios y adhesión manifiesta a la república, antes de aquella época, ó de la Asamblea inmediata, [hubieran merecido] la honrosa distinción de ciudadanos».

En El Redactor de la Asamblea, órgano periodístico oficial de la institución ${ }^{25}$, se consideró el problema de la ciudadanía con respecto al ejercicio de

24 Urién, 1913: 321-326.

25 Recuérdese que las actas de la Asamblea se han perdido y que lo que nos ha llegado de ella son las notas y algunos de sus decretos publicados en El Redactor [...] que era su ór- 
cargos públicos de los reputados españoles, relacionado con la tensión entre las fuerzas moderadas y las revolucionarias. En la sesión del día 3 de febrero de 1813 se acordó: «la remoción de los españoles europeos, de todos los empleos civiles, eclesiásticos, y militares, exceptuando solo aquellos, que obtuviesen titulo de ciudadanía en el término prefixado». En la misma sesión se aclara y amplía esta decisión, destacando cuál había sido la situación al respecto desde 1810:

[...] era de esperar que la sangre de los injustos fuese el primer indicio de la revolución; pero lejos de este doloroso extremo, los españoles europeos han continuado hasta hoy en sus empleos con peligro de la administración, con abuso de nuestro sufrimiento y odio de los mas dignos americanos ${ }^{26}$.

Como en las pragmáticas españolas del siglo XVII y XVIII, se reconocían excepciones según los casos y condiciones de los europeos españoles ${ }^{27} \mathrm{y}$, probablemente, también de acuerdo con los cargos que ocuparan ${ }^{28}$. El mismo decreto prescribió que:

En esta misma medida ha mostrado también la Asamblea la imparcialidad de sus designios, distinguiendo con el título de ciudadanía á todos los españoles europeos que han adquirido un derecho incontestable á la gratitud americana ${ }^{29}$.

Este otorgamiento de «título de ciudadanía» tenía más bien el carácter de una carta de naturaleza ya que una de las justificaciones o condiciones con que se otorgaba en España era por haber prestado favores y servicios a la Corona; en este caso el servicio cumplido merecedor «á la gratitud americana», vale decir reemplazando la gracia real por la de la Asamblea ${ }^{30}$. Por este motivo se aclamaba en el final del decreto:

gano de difusión oficial. Se publicaba los sábados, dirigido por Fray Cayetano Rodríguez, siendo Bernardo de Monteagudo su pluma más destacada (Lambré, 2010).

26 Ibidem: 17-18.

27 Era bastante común, hasta el siglo XVIII, que en esta monarquía múltiple los reyes tuviesen ministros ajenos a España. Recordemos al marqués de Squillace en el reinado de Carlos III. Véase en Fernández Albaladejo, 2007: 235-236.

28 Salvatto y Carzolio, 2015: 677-678.

29 Lambré, 2010: 18

30 Salvatto, 2013. Esta continuidad en las formas jurídicas entre el Antiguo Régimen y la época independiente en Buenos Aires puede verse también en las fórmulas para el otorgamiento de tierras, toda vez que las Donaciones del Directorio, seguían los lineamientos de las mercedes reales, sirviendo de justificación para la concesión el reconocimiento de los servicios brindados a los nuevos gobiernos, tal como antes se había hecho con los servicios prestados a la corona (Banzato, 2002. Infesta, 2007). 
¡Pueblos! Jamás confundáis la virtud con el crimen, ni la pasión con el deber: jurad un odio eterno á la tiranía, paro [sic: pero] amad á todos los hombres porque su destino es igual al vuestro; y cumplid con todos los deberes que imponen un verdadero patriotismo ${ }^{31}$.

A diferencia - por ejemplo- de la carta de ciudadanía gaditana (1812) que se relacionaba con determinadas condiciones que debía cumplir el postulante a obtenerla, la distinción como ciudadano en este caso dependía de los servicios prestados a la patria, del pedido de ciudadanía del extranjero solicitante $\mathrm{y}$ de la resolución de este pedido (otorgamiento o rechazo) por parte de las autoridades designadas por la Asamblea.

En un expediente consultado en el Archivo Histórico de la Provincia de Buenos Aires, consta una serie de copias de notas que reunió Miguel de Azcuénaga, en su carácter de Gobernador Intendente de Buenos Aires. Los originales le fueron enviados por la secretaría de la Asamblea y él a su vez los remitió para su conocimiento al Tribunal General de Hacienda durante el mes de febrero de $1813^{32}$. En estas notas, la Asamblea fue dando cuenta de las resoluciones sobre concesiones y denegatorias de ciudadanía a los «Españoles Europeos empleados» durante los días 11, 13, 22, 23, 25 y 27 de ese mes. Las listas contienen un total de 95 personas, identificadas a través del cargo que ejercían en la burocracia imperial heredada y la que se fue generando con los nuevos gobiernos, excepto los casos de Pascual Ruiz Huidobro y Prudencio Murguiondo seguramente por ser sobradamente conocidos ${ }^{33}$. En total fueron concedidas 41 cartas de ciudadanía y negadas 54, teniendo en cuenta que en los casos de Ruiz Huidobro, Prudencio Murguiondo, Saturnino José Álvarez, Antonio de Pósiga, Juan José Moreno, los implicados presentaron una solicitud de revisión a la denegatoria y consiguieron revocarla.

31 Lambré, 2010: 19.

32 Agradecemos a José Sovarzo la información sobre la existencia de este documento fuera de catálogo: Archivo Histórico de la Provincia de Buenos Aires (en adelante AHPBA), Real Audiencia, Varios 1771-1813. Cánter (1962b: 145-146) utilizó documentos del Archivo General de la Nación, Buenos Aires (en adelante AGN) que, evidentemente, coinciden con éste, ya que menciona las mismas fechas de las resoluciones de la Asamblea, con la excepción de un documento del día 27 de febrero en el que se denegó la carta de ciudadanía a Manuel de la Presilla y que no está en nuestra lista del mismo día. A su vez sí coinciden Francisco de Paula Saubidet, Inocencio Agrelo, Damián Castro y Manuel Fernández Puch. Las listas se encuentran transcriptas en Salvatto y Banzato, 2013.

33 Ambos eran militares españoles de larga trayectoria, que ejercieron altos cargos en el Río de la Plata, participaron en las invasiones inglesas y luego apoyaron la revolución $(\mathrm{Cu}-$ tolo, 1975: 723; 1983: 493-494). 
Una comparación de las listas nos permite presumir que quienes tomaban las decisiones tenían un conocimiento muy ajustado de los movimientos y opiniones de los solicitantes. No hay una distinción por oficio, sino que se encuentran en ellas funcionarios de diferentes áreas: principalmente guerra (39 personas) y hacienda (33), dos especialidades con información muy sensible para cualquier gobierno. Luego podemos considerar a otras 17 personas en varios cargos, 4 eclesiásticos y a los nombrados Ruiz Huidobro y Murguiondo.

Entre los miembros del ejército, 18 consiguieron su carta de ciudadanía y les fue negada a 21. Entre los primeros, los tenientes Agustín Murillo e Hipólito Bouchard, quienes el año anterior habían participado en el combate de San Lorenzo a las órdenes de San Martín ${ }^{34}$, al veterano coronel Antonio de Olavarría ${ }^{35}$, al recientemente designado comandante militar de la Ensenada, Bernardo Bonavía ${ }^{36}$ y al Teniente Coronel Juan José Moreno, agregado al Estado Mayor $^{37}$.

Para los empleados en lo que denominamos ramo de Hacienda, los rechazos (23) fueron mucho más numerosos que las concesiones (10). Otros nueve empleados de varias oficinas fueron nombrados ciudadanos ${ }^{38}$, aunque ocho no lo lograron. Los eclesiásticos también fueron considerados: les fue concedida la ciudadanía a Fray Juan Noble Carrillo, de la Orden de San Francisco ${ }^{39}$, y

34 Véase Cutolo, 1968: 514-515.

35 Había llegado con la expedición de Pedro Cevallos en 1777, continuó su carrera en el cuerpo de Blandengues y como comandante del fuerte de Salto, participó en las invasiones inglesas de 1806 y no pudo acompañar a la expedición al Paraguay a la órdenes de Belgrano para la que había sido nombrado por la enfermedad que lo llevó a la muerte (Cutolo, 1978: 130).

36 Con una larga trayectoria en la armada española, fue destinado a Buenos Aires en 1802 y nombrado Gobernador de las Islas Malvinas. En 1811 revistaba en Montevideo cuando por sus ideas liberales fue apresado y enviado a España. Escapó tras la invasión de Napoleón y en enero de 1813 fue designado en el cargo de Comandante del Fuerte de la Ensenada de Barragán (Cutolo, 1968: 491).

37 Llegó como capitán general del puerto de Buenos Aires a fines del siglo XVIII, su familia era muy reconocida en la época siendo su casa un centro de sociabilidad importante en la ciudad (Cutolo, 1975: 660).

38 Entre ellos el médico Agustín Eusebio Fabre, quien había tenido una larga trayectoria en distintos destinos hasta que recaló en Buenos Aires, siendo uno de los autores del proyecto para la Escuela de Medicina que se fundó en 1801 y conjuez del Protomedicato, participó en las invasiones inglesas, en el cabildo abierto del 22 de mayo y en la campaña de Belgrano al norte (Cutolo, 1971: 9).

39 Franciscano, predicaba y fue maestro en el convento de la Recolección de San Pedro (Otero, 1899: 4 y http://www.infoguiasanpedro.com/informacion/san-pedro/historia/los-primeros-maestros-en-san-pedro.html. Consultado el 21/01/14). 
a Manuel Alvariño ${ }^{40}$, pero les fue negada a dos organistas de la catedral, el muy conocido Juan Bautista Goiburu ${ }^{41}$ y a Manuel de la Lendexa, de quien no tenemos información.

En la sesión del 9 de abril de 1813 se planteó nuevamente el problema del otorgamiento del título de ciudadanía a españoles europeos. La consulta de un miembro de la Cámara de Apelaciones al Poder Ejecutivo sobre la condición de los escribanos europeos motivó el siguiente decreto:

Á virtud de la consulta hecha por el ciudadano Diaz Vélez, miembro de la cámara de apelaciones al Supremo Poder Fxecutivo [Sic: E] y de este á la Asamblea General, sobre si el europeo español escribano de alzadas D. Tirso Martínez deberá continuar en el exercicio de sus funciones, no teniendo carta de ciudadanía; se declaró, que todos los escribanos españoles europeos, de cualquier clase que fueran, están comprendidos en el decreto de 3 de febrero último, expedido sobre los empleados europeos; y que para obtener ciudadanía se prescribe á los de esta ciudad el término de 8 días, y para los existentes en todos los territorios de las provincias unidas el de 3 meses, contados desde la fecha del presente decreto. Firmado=Pedro Agrelo, presidente en turno. $=$ Hipólito Vieytes, diputado secretario ${ }^{42}$.

Evidentemente, luego de las purgas que se venían realizando, tanto en la Audiencia como en el Cabildo ${ }^{43}$, uno de los problemas a los que con seguridad se enfrentó la Asamblea General Constituyente fue la falta de cuadros burocráticos locales americanos, que pudieran reemplazar a los peninsulares, por lo cual éstos continuaron en sus funciones a partir de las presentaciones que hicieron los reputados españoles europeos en la Cámara de Apelaciones. El otorgamiento de una carta de ciudadanía a los escribanos que la solicitaran garantizaba, si la obtenían, cierta continuidad de las prácticas del derecho indiano en el llamado derecho patrio, pues el primero nunca había sido dero-

40 Dominico, nacido en Galicia, entró a la Orden en Buenos Aires, habiendo sido preceptor de Gramática y Lector de Filosofía, regente de estudios y más tarde prior en Asunción, luego fue prior en Buenos Aires, donde en 1810 adhirió a la causa revolucionaria (Rey Castelao, 2001: 49).

41 Sacerdote y músico, cuando era niño fue traído a Buenos Aires por su tío, el deán de la Catedral, siendo nombrado organista en 1785, cargo que ejerció hasta el 12 de febrero de 1813, porque se negó a renunciar a la nacionalidad española, muriendo poco después (Cutolo, 1971: 328).

42 Lambré, 2010: 74. José Miguel Díaz Vélez, luego de recibirse de abogado en Chuquisaca vivió en Concepción del Uruguay, donde ocupó los cargos de administrador de correos y Alcalde de Primer Voto del Cabildo, presidiendo este cuerpo cuando se reconoció a la Primera Junta de Buenos Aires. Luego fue nombrado por Belgrano Comandante General de los partidos de Entre Ríos. En 1812 fue designado en el cargo que se menciona arriba (Cutolo, 1969: 566-567).

43 Candioti, 2012: 291. 
gado. Obsérvese, además, que no se mencionaban condiciones especiales para obtener la ciudadanía, ya que dependía de la resolución -como se dijo más arriba- de las autoridades designadas por la Asamblea. No se verificaban criterios de residencia por determinada cantidad de años, ni por edad, ni por tenencia de un patrimonio inmueble o por ser propietario de un monto de dinero que le permitiera ejercer oficio útil.

La intención de establecer un control efectivo sobre quiénes eran ciudadanos se manifestó en la propuesta de Monteagudo aprobada en la sesión del 4 de agosto de 1813, por la cual se establecía que en los cabildos se abrirían «registros cívicos» en los cuales se haría constancia de los nombres de los ciudadanos.

El proceso de la Asamblea General Constituyente (1813-1815) es de suma importancia para nuestro trabajo puesto que las autoridades de Buenos Aires suprimieron la fórmula utilizada desde 1808 para justificar el hecho de constituirse en depositarios de la soberanía: el vínculo con la corona española y el nombre de Fernando VII como cabeza de ese vínculo ${ }^{44}$. El poder ejecutivo, ejercido desde 1814 por el Director Supremo del Estado, junto a Gobernadores y Consejos de Estados, asume dicho vínculo con los vecinos de las distintas ciudades cabeceras y pueblos del ex virreinato, pero la nueva relación no goza de la antigua legitimidad en este amplio territorio.

En el Estatuto Provisional de 1815 se hizo mención en el Articulo $1 .^{\circ}$ a la elaboración de un registro público en dos libros:

[...] en uno se inscribirán indispensablemente todos los Ciudadanos con expresión de su edad, y origen, sin cuyo requisito no podrán sufragar en los actos públicos [...]; y en el otro los que hayan perdido el derecho de Ciudadanía, o se hallen suspensos de ella.

Las condiciones de los inscriptos en el primer libro son las referentes a la restricción por minoridad y origen, ambas cuestiones reglamentadas en los siguientes artículos, y en el segundo libro las correspondientes a suspensiones y pérdidas del derecho de ciudadanía por causas luego indicadas. En el Artículo 2 se definió al ciudadano:

Todo hombre libre, siempre que haya nacido y resida en el territorio del Estado, es Ciudadano; pero no entrará al ejercicio de este derecho, hasta que haya cumplido 25 años, o sea emancipado.

También lo era «Todo extranjero de la misma edad, que haya residido en el país por más de cuatro años[...]» (Art. 3, Cap. III).

44 Canter, 1962b: 44. 
Las condiciones eran semejantes a las de la obtención de la vecindad en épocas del imperio por parte de un forastero, teniendo como primera obligación la residencia por más de cuatro años. Pero también se exigía que el solicitante «se haya hecho propietario de algún fondo, al menos de cuatro mil pesos, o en su defecto ejerza arte ú oficio útil al país [...]», así, siempre y cuando supiera leer y escribir podría sufragar ${ }^{45}$. Se reconocía el voto activo para los casos de los extranjeros con las condiciones antes nombradas, pero se contemplaba la posibilidad de que obtuvieran el voto pasivo como se especifica en el Artículo 4 (Cap. III):

A los diez años de residencia tendrá voto pasivo, y podrá ser elegido para los empleos de República, mas no para los del Gobierno: para gozar de ambos sufragios debe renunciar antes a toda otra Ciudadanía.

La renuncia de la ciudadanía extranjera era condición necesaria para poder ejercer el voto activo y pasivo pero no alcanzaba para el desempeño de los cargos de gobierno. Sin embargo, para el caso de los españoles europeos, ambos sufragios quedaban en suspenso hasta el reconocimiento de la independencia de los rioplatenses por la península (Art. 5, Cap. III).

Lo establecido en el Artículo 6 se corresponde con lo planteado durante la Asamblea General Constituyente, puesto que nuevamente surgieron las excepciones:

Los Españoles sin embargo decididos por la libertad del Estado, y que hayan hecho servicios distinguidos a la causa del País gozarán de la Ciudadanía; pero deben obtener la correspondiente Carta, que expedita por ahora hasta el Congreso General el Jefe respectivo de la Provincia asociado del Ayuntamiento de su Capital.

Obsérvese que no habiendo tal Congreso General, los Cabildos de las principales ciudades del ex virreinato quedaban a cargo del otorgamiento o rechazo de la carta de ciudadanía y de la evaluación de las condiciones del aspirante. En el Articulo 7 (Cap. III) se incorporó una fórmula conocida en la Constitución de Cádiz de 1812 para la inclusión o exclusión de los libertos, compárese con la que hemos mencionado más arriba:

Los nacidos en el País, que sean originarios por cualquier línea de África, cuyos mayores hayan sido esclavos en este continente, tendrán sufragio activo,

45 En 1815, en Buenos Aires una vaca costaba 2 pesos, un caballo 3 y una hectárea 0,15 (Garavaglia, 2004: 142 y 144), de modo que no cualquiera llegaba a un patrimonio de 4.000 pesos. 
siendo hijos de Padres ingenuos; y pasivo los que ya estén fuera del cuarto grado respecto de dichos sus mayores.

La pérdida y suspensión de la ciudadanía se presentan en el Capitulo V:

La Ciudadanía se pierde por la naturalización en el País Extranjero; por aceptar empleos, pensiones, o distinciones de nobleza de otra Nación: por la imposición legal de pena aflictiva o infamante, y por el estado de deudor dolosamente fallido, si no se obtiene nueva habilitación después de purgada la nota (Art. 1).

La Ciudadanía se suspende por ser deudor a la Hacienda del estado, estando executado; por ser acusado de delito, siempre que este tenga cuerpo justificado y por su naturaleza merezca pena corporal, aflictiva o infamante; por ser doméstico asalariado; por no tener propiedad u oficio lucrativo y útil al País; por el estado de furor o demencia (Art. 2).

La suspensión de la ciudadanía también se reglamentaba en los mismos términos del Artículo 25 de la Constitución de Cádiz. Hay que tener en cuenta que la rapidez con que se suceden los acontecimientos abocaron a las personas a tomar decisiones que las descolocaron ante el cambio de la situación.

\section{PATRIA y PAN EN LA FRONTERA DE Buenos Aires DeSPuÉS DE LA REVOluCión}

El impacto de estas medidas tomadas contra los españoles repercutió en la campaña de Buenos Aires, tanto en la impugnación al derecho de las personas de otras nacionalidades para ejercer una determinada actividad, como en el reconocimiento de la utilización de la condición de patriota o patricio para obtener la protección del nuevo gobierno. Como afirma Di Meglio

[...] esa noción de patria se ubica como parte de una tríada de elementos fundamentales de la organización de la monarquía española junto a rey y la religión [...] pero esta tríada colonial se desarmó: la revolución se hizo en nombre del rey pero pronto se volvió contra su figura [...] la patria quedó como el principio aglutinador, con fuertes contenidos emotivos y afectivos en su invocación ${ }^{46}$.

Analizaremos en este apartado una disputa por la instalación de un panadero catalán en el pueblo de Chascomús, donde entró en competencia con las amasadoras de pan, entre 1812 y 1813.

Según el relato del comandante de la guardia, Fermín Rodríguez, el catalán Don José Comas había obtenido carta de ciudadanía, pero a mediados de

46 Di Meglio, 2008: 116 y 120. 
1812, cuando la presión sobre los peninsulares se hacía cada vez más pesada a medida que la lucha en el campo de batalla y el sostenimiento del gobierno de Buenos Aires aumentaba la tensión contra el grupo español europeo, abandonó el puerto de la Ensenada, donde había estado asentado, «nada mas qe $\mathrm{p}^{\mathrm{r}}$ precaucion, de qe como á Europeo, le embolviesen en sospechas, quando se presentaban los barcos enemigos» motivo que impulsaba a la internación en el territorio de los extranjeros, en caso de guerra y decidió solicitar permiso para instalarse en Chascomús ${ }^{47}$. De oficio panadero, pero con cierto giro pues también instaló marquetería y jabonería, Comas inició sus labores colocando en las pulperías panes de mejor calidad que el que se venía consumiendo en el pueblo, hasta que la presión de las amasadoras locales sobre el comandante ${ }^{48}$, hizo que éste le solicitara que dejase de elaborarlo y que se dedicara sólo a «rosquetes y otros dulces ${ }^{49}$.

El delicado equilibrio entre oferta y demanda comenzó a resquebrajarse, en una comunidad de aproximadamente 800 habitantes $^{50}$, en la que evidentemente el pan era esencial en la dieta y no necesariamente se manufacturaba en el seno de los hogares (aún en los pueblos de campaña). Según el comandante, cuando fueron «internados» los españoles en septiembre de 1813, ante el aumento de los consumidores, la producción de las panaderas se tornó insuficiente. Con cierta picardía, rápidamente encontraron la solución reduciendo el peso de los panes hasta un límite a causa del cual el comandante decidió que debía intervenir. Por un lado reunió a las panaderas y les ordenó que el pan debiera pesar lo que se indicaba en el arancel del Cabildo; al mismo tiempo le levantó a Comas la prohibición de hacerlo.

El reingreso de su competidor al mercado provocó la indignación y protesta de las mujeres. El 1. ${ }^{\circ}$ de octubre de 1813 , Jacinta Suárez «y a nombre de mis compatriotas, las panaderas de esta Guardia», presentaron un escrito

${ }^{47}$ AHPBA, C 13, A 1, L 6, exp. 1bis, f. 10v.

48 Hasta que los antiguos fuertes de la frontera de 1780 fueran sustituidos en sus funciones fundamentales de defensa por los de las nuevas fronteras que se fueron abriendo en la década de 1820, era común la superposición de la autoridad militar de los comandantes y la civil de los alcaldes de los pueblos nucleados alrededor de estas precarias defensas. En este caso, las amasadoras no estaban de acuerdo con las decisiones del comandante, pero no cuestionaron su autoridad y tampoco recurrieron al alcalde, que en ese año fue Gregorio Almirón (Ver, para la lista de alcaldes de Chascomús, Galarza, 2012).

49 Seguramente los rosquetes son los mismos que han permanecido en la pastelería de la provincia de Santiago del Estero, donde se venden cotidianamente en las calles. También pueden encontrarse recetas actuales de España en la web.

50 El cálculo es muy aproximado, ya que no está claro en el padrón de 1815 hasta dónde llega el espacio denominado «Chascomús» en la fuente. Cfr. Banzato, 2005: 102. 
al Comandante negando que hubiera escasez y quejándose de que permitirle a Comas amasar pan significaba «desamparar a las pobres Patricias qe estan sus hijos y sus maridos sirviendo al Estado y a la Patria con el corto socorro $\mathrm{q}^{\mathrm{e}}$ adquirimos $\mathrm{p}^{\mathrm{a}}$ nuestra manutencion $\rangle^{51}$.

Acusaron a su competidor de intentar acaparar el trigo pagándolo más caro a los productores y le recordaron al Comandante que en una ocasión anterior, cuando vinieron otros catalanes con el mismo propósito, él los rechazó aunque ahora amparaba a éste para que «llene su talega». Finalmente, aceptaban vender el pan según lo indicaba el Cabildo, pero insistían en que sus intereses estarían defendidos si no amasaba Comas, pues «no lo podremos seguir si la pasion reyna por delante pero la Patria nos amparará $\mathrm{p}^{\mathrm{r}}$ la razon $\mathrm{q}^{\mathrm{e}}$ tenemos lo q á Vm pido y suplico en mi nombre, y de todas las demas nos mire con aquella atencion $\mathrm{q}^{\mathrm{e}}$ merecemos como pobladoras antiguas de esta población ${ }^{52}$.

Si Di Meglio ha mostrado claramente en el ámbito urbano la difusión del concepto de «patria», este ejemplo nos permite detectarlo hasta en lo más recóndito de la campaña que rodeaba a la ciudad revolucionaria, pues tal como él dice aquí también «se convirtió en aglutinante social [...] que igualaba simbólicamente a todos aquellos que apoyaban la causa contra los mandones, los europeos» ${ }^{53}$. Aún así, siempre había lugar para una acción que en el plano local buscara cierta concordia, ya que el Comandante permitió que el panadero catalán hiciera su descargo, argumentando éste que, cuando se le volvió a permitir amasar, fue por «el bien publico» ya que si bien «bi concurrir $\mathrm{p}^{\mathrm{r}}$ la expulción de los Europeos de la Capital tanto, consumidero, no $\mathrm{p}^{\mathrm{r}}$ esto minore el pan», aunque sí lo hicieron «las patricias», cuyo pan resultó ser bastante más liviano, de modo que aconsejaba, en una lección de marketing avant la lettre:

pues quieren las patricias, bender quanto puedan amasenlo trabajelo bien, dénle el peso del aransel, de esta suerte, no les faltara consumo, pero pensar qe teniendo mi pan diez onzas y el suyo seis, escasas a de ser preferido no lo creo, aunq e pongan sobre cada pan letras grandes, que digan patria y patricias.

La fina ironía del catalán nos advierte sobre los usos de los conceptos y las identidades en la vida cotidiana de un pueblo. En su concepción, las lugareñas estaban escondiendo una cuestión de monopolio del pequeño mercado del pan en nombre de la patria y de su condición de patriotas. Por último,

\footnotetext{
51 AHPBA, C 13, A 1, L 6, exp. 1bis, f. 1.

52 Idem y 1v (énfasis y subrayados en el original).

53 Di Meglio, 2008: 121.
} 
ofrecía dejar de amasar pan con tal que «no se me buelba a incomodar $\mathrm{p}^{\mathrm{r}} \mathrm{q}^{\mathrm{e}}$ hasi es de justicia» ${ }^{54}$.

No le bastó a la decidida representante de las panaderas el ofrecimiento que hizo Comas de retirarse del negocio. Formó expediente con las dos notas y presentándose a las autoridades de Buenos Aires insistió en la oposición americano-español como fuente del conflicto:

veo con dolor qe só la capa del bien publico con qe intenta desfigurar sus procedimitos protexe desidida y parcialmte a aquel Español qe segn las medidas qe adopta, y le sugiere elespiritu de codisia que en herencia le transmitieron sus mayores, va a esponer a la mendisidad y reducir á hambre, mui atendible numero de virtuosas americanas, qe hoy mas qe nunca son dignas de la concideracion, y beneficios.

En ningún momento la representante de las panaderas consideró que Comas tenía una carta de ciudadanía que lo habilitaba a ejercer su oficio ni tampoco lo reconoció como vecino, puesto que lo acusan de faltar a un elemento fundamental de la vecindad, que es la solidaridad. Los argumentos vertidos en su escrito anterior se vieron enriquecidos en su nueva presentación ${ }^{55}$, ya que retomó la acusación a Comas de pagar el trigo a precio más alto para acaparar el mercado, con la impugnación al comportamiento secular de los españoles y recordando los sacrificios realizados por las mujeres, sus maridos e hijos.

Estas combinaciones no estan al alcanse de Rodrigues, y tampoco lo esta qe los españoles para aglomerar caudales jamas respetaron medio algo, corrompian las costumbres, y propagaban los vicios. Si Comas pone en corriente su Panaderia, si le produse las utilidades de un $100 \mathrm{ps}$ ¿qe le importan qe mueran de hambre mis protegidas madres o viudas de hijos qe actualmte empuñan la espada en la justa defensa de su suelo, o de esposos qe han sacrificado su vida en el campo de la Gloria?

En última instancia, según Jacinta Suárez, Comas podía dejar de amasar pan pues tenía otras formas de ganarse la vida y procurar el sustento para su familia:

sin causarnos los daños que por 300 años no interrumpidos hemos experimentado de sus ascendientes, qe hacian el comercio exclusivamte en todos sus ramos sin qe

\footnotetext{
54 AHPBA, C 13, A 1, L 6, exp. 1bis, f. 3-4.

55 En este punto, bueno es recordar que lo importante aquí es lo que las autoridades tuvieron a la vista a la hora de decidir, más que debatir si los argumentos esgrimidos por una panadera que no podía siquiera firmar eran propios o de quien le escribía las presentaciones.
} 
se les opusiese traba alga al paso qe nosotras yaciamos embueltas entre cadenas, y agoviadas con el peso de la miseria mas humillante ${ }^{56}$.

El comandante presentó una relación muy detallada de lo ocurrido para justificar su actitud, que nos ha permitido reconstruir el conflicto. Acompañó el escrito con dos panes, uno de siete y otro de once onzas, elaborados por las «amasanderas» el primero y por Comas el segundo, con el fin de que «Gradue V.E. si el comprador preferirá este ultimo al primero; y digaseme: si encargado de esta Poblacion, podria aun quando fueran mis Hijas, permitirles el qe estafasen la vecindad, para mejorar su fortuna? ${ }^{57}$

Jacinta Suárez, casada con Manuel Ferreyra, vivía en la guardia y pueblo de Chascomús, por lo menos, desde 1788. Y desde esa época se conocían con Fermín Rodríguez, pues ambos figuran en el padrón que se levantó ese año ${ }^{58}$. En el siguiente recuento poblacional realizado en 1815, dos años después del conflicto que analizamos, Jacinta, de 48 años, y Manuel, de 60, seguían en el pueblo con sus tres hijos y una esclava. Él era de Areco y declaró ser de oficio pulpero, ella era de Ranchos y no está registrada como panadera. En cuanto a José Comas, figura como panadero, catalán, de 36 años, casado con la porteña Isabel Álvarez, con tres hijos nacidos en Ensenada y el último en Chascomús ${ }^{59}$. Es decir cumplía con la condición de estar casado con una natural y tenía fondos propios como para montar una industria útil, condiciones necesarias para obtener la carta de ciudadanía.

En cuanto a Don Fermín Rodríguez tenía 71 años, había enviudado y vivía con su hijo Miguel, de 24, ambos con el oficio de estancieros ${ }^{60}$. Merece un párrafo aparte este funcionario que ejerció la autoridad militar en Chascomús, desde la fundación misma del fuerte por Pedro Nicolás Escribano. Fermín Rodríguez estuvo en la campaña fundadora, luego ascendió a capitán de milicias en la primera década del siglo XIX y más tarde alcanzó la comandancia del fuerte. Como otros militares de la época ${ }^{61}$, también tomó tierras en las inmediaciones, al mismo tiempo que se fundaba la guardia; sus dominios abarcaban unas 14.800 hectáreas más otras 6.000 sobre el río Salado, que fueron solicitadas por sus descendientes y escrituradas en donación del Direc-

56 AHPBA, C 13, A 1, L 6, exp. 1bis, f. 5-6.

57 Ibidem, f. $12 \mathrm{v}$.

58 Banzato y Quinteros, 1992.

59 Vivían con ellos un esclavo y tres esclavas, lo que da cuenta de una posición económica más que acomodada, sobre todo porque evidentemente los esclavos eran familia ya que había una menor de 6 años nacida en Ensenada.

60 AGN, X-8-10.

61 Néspolo, 2006; 2012. Alemano y Carlón, 2009. Alemano, 2013. 
torio en 181962. Para la época que nos ocupa, su hijo Martín había participado de la defensa de Buenos Aires durante las invasiones inglesas y era un activo protagonista de la Revolución de Mayo, habiendo sido uno de los comandantes de milicias que sostuvo la posición de Cornelio Saavedra durante la asonada del 5 y 6 de abril de 1811 y destinado al Ejército del Norte en junio de $1812^{63}$. De modo que en esos años turbulentos, desde su pueblo y fuerte de frontera, Fermín Rodríguez tenía llegada directa al núcleo del poder central en Buenos Aires.

Según lo que llegó a las autoridades, las panaderas planteaban que un extranjero estaba sacándolas del mercado con la connivencia de la máxima autoridad local; para el catalán y el Comandante no se trataba más que de un ardid de las mujeres que estaban aprovechando la coyuntura política desfavorable para los españoles europeos para acusarlo injustamente y poder vender el pan a su antojo en precio y calidad. Si cada uno estaba haciendo uso de los mecanismos que la justicia admitía para la defensa de sus intereses, no importa aquí que su acusación fuese justa o injusta, las autoridades de Buenos Aires optaron por una solución salomónica, indicando que mientras se esperaba la intervención final del Gobernador Intendente, el peso del pan debía ajustarse a lo indicado por el arancel del Cabildo y en cuanto a Comas podía seguir vendiendo pan, pero «deve fijarsele una contribucion mensual qe con utilidad del Estado sea una ventaja indirecta concedida a la industria de los naturales de este suelo» ${ }^{64}$, un ejemplo de política proteccionista en el nivel local, que no se alejaba mucho de otras practicadas en la época ${ }^{65}$. Nada de lo señalado en torno a la preeminencia para las patriotas y antiguas pobladoras que reclamaba Jacinta Suárez fue considerado en esta escueta nota al margen con la que se dio por finalizado el expediente.

En Chascomús, el del comercio no fue el único ámbito en que las expresiones de patriotismo o manifestación de ciudadanía fundamentaban una petición a las nuevas autoridades o el de «español» para descalificar al oponente ${ }^{66}$. En esos años, Juan Lorenzo Castro querelló al «Español» Calleja

62 AHPBA, Escribanía Mayor de Gobierno (en adelante EMG), 152-12121-1819. AGN, Protocolos, r. 1, 1822, f. 11v. y r. 6, 1825, f. 579.

63 Levene, 1962b: 331. Cutolo, 1983: 299-303.

64 AHPBA, C 13, A 1, L 6, exp. 1bis, f. 10 anotación al margen.

65 Amaral, 1993. Otra continuidad con el sistema de prácticas del Antiguo Régimen, la constituía la tradicional política de la exclusividad de usufructo y reserva del comercio local para los vecinos, y la exclusión del forastero-extranjero que puede verse en las ordenanzas de los siglos XV y XVI en España (Domínguez Ortiz, 1959. Pérez Bustamante y Baró Pazos, 1988. Bourin y Durand, 2001).

66 Fradkin y Ratto, 2010: 78. 
acusándolo de haber quebrantado una de las costumbres productivas, que estipulaba los montos que debían pagarse por comercializar ganado de un convecino y, de igual manera que las panaderas, abundaba en históricos reclamos: «De suerte que Calleja poseido de la codicia de sus mayores creó fundar un Mayorazgo sobre la ruina de nuestros intereses [...]» ${ }^{67}$.

Como han planteado otros autores, en los trámites de la época la identificación como vecino y la ocupación «que le otorgaba cierta identidad social, [...] se sumaron las calificaciones de "ciudadano" y "americano" ${ }^{68}$. En los años siguientes, hacia 1819, cuando el gobierno estaba otorgando tierras en donación y en moderada composición ${ }^{69}$, Don Juan Antonio Izurieta declaró que hacía más de veinte años que estaba asentado con «siete hijos que tengo y trabajan a mi par (todos americanos)», y Don Antonio Quinteros también se identificó como «americano» ${ }^{70}$. Entre los muchos testimonios, que además agregaban los servicios al Estado como anteriormente se hacía con los servicios a la Corona, don Santiago Roxas se presentó solicitando el predio que hacía muchos años habitaba y en el que había fundado una estancia,

a merito de los conciderabes servicios, $\mathrm{q}^{\mathrm{e}}$ ya como Pobladr ya como soldado, y ya como vezino he prestado a su franquicia y fomento, y de los auxilios $q^{\mathrm{e}}$ como Hazendado he dado a mi Patria en caballos y ganado Bacuno, y ultimam ${ }^{\text {te }}$ la abanzada edad en $\mathrm{q}^{\mathrm{e}}$ me hallo, y la numerosa familia $\mathrm{q}^{\mathrm{e}}$ he procreado $\mathrm{y}$ alimentado dando a la patria tres varones $\mathrm{q}^{\mathrm{e}}$ hoy sirven en la Milicia [...] dando a mi posteridad, $\mathrm{p}^{\mathrm{r}}$ este medio, un signo $\mathrm{q}^{\mathrm{e}}$ eternize su reconocimiento y publique la rectitud y beneficencia $\mathrm{q}^{\mathrm{e}}$ distingue a $\mathrm{n}^{\text {tro }}$ Gobierno Patrio $[\ldots]^{71}$.

En los litigios por la posesión y propiedad de la tierra, también se utilizaron los argumentos de los servicios a la patria para justificar el derecho al suelo. Por ejemplo, Don Juan Arriola, emparentado con una familia que tenía un siglo de asentamiento en los límites entre Ranchos y Chascomús, cuestionó que en 1820 Felipe Chavarría recibiera una donación del directorio y empezara a mensurar, preguntándose si no tenía más derecho a la tierra que el nuevo solicitante,

${ }^{67}$ AHPBA, C 13, A 2, L 9, exp. 39, 1813. Hemos trabajado este tema en Galarza y Banzato, $2014 \mathrm{e}$

68 Fradkin y Ratto, 2010: 77.

69 Banzato, 2005.

70 AHPBA, EMG, 145-11690-1819 y 152-12081-1819.

71 Ibidem, 152-12145-1819. Del mismo tenor, los casos de Martín Marín (AHPBA, EMG, 146-11792-1819), Hilario Irazoqui (ibidem, 145-11684-1821), Josefa Chávez (ibidem, 14411642-1819) y Santiago Rojas (ibidem, 152-12145-1819). 
[...] pues á mas del derecho de posecion ser un vecino afincado y con familia, los inmensos perjuicios que estoy sufriendo ya en mi persona como en donativos para la Patria y contribuciones para la Guardia? Y que será el pago el arrojarme para que venga uno de afuera sin tener no solo una cabeza de ganado ni el mas minimo palo puesto ni haber sufrido los perjuicios como yo he sufrido, y que aun contra la voluntad del mismo Gobierno quiera hecharme y despojarme de lo que con el sudor de mi rostro y honradamente he adquirido para mantener a mi muger e hijos? $?^{72}$

Unos años más tarde, se inició un largo litigio por unos terrenos concedidos en enfiteusis. El fiscal consideró, en 1834, en pleno rosismo, que debía dársele a Josefa Aguilar una porción de tierra que no alcanzaba los mínimos que la ley pautaba. Se trataba de una mujer dos veces viuda, que además de ser antigua poseedora del terreno había tenido veinte hijos, muchos de ellos cumpliendo servicios al estado en el ejército y que en ese momento, era acosada por las pretensiones de dos extranjeros (los comerciantes Guillermo Ford y Mariano Baudrix). Alegó el fiscal:

Y quienes S.E. pretenden que V.E. reboque su providencia, y destruya una familia venemerita natural del país? Precisamente dos individuos que no son naturales de el y precisamente los que no tienen mejor derecho ${ }^{73}$.

En este sentido, el fiscal estaba interpretando la ley, en beneficio de una mujer cuyo ciclo de vida cumplía con muchas de las antiguas tradiciones de Antiguo Régimen readaptadas a los nuevos tiempos: la condición de nacimiento y los servicios de $\operatorname{armas}^{74}$.

\section{CONCLUSIÓN}

Surgen diversos problemas para establecer un balance del proceso que comenzó con el llamado a la Asamblea General Constituyente (1813) y la puesta en vigencia del Estatuto provisional de 1815, respecto del ejercicio de cargos públicos y oficios en el Río de la Plata. En primer lugar existen pocos trabajos que observen tanto las relaciones entre la ciudad y la campaña, tanto en el territorio bonaerense como en los de otras provincias. En segundo lugar,

72 Ibidem, 149-11935-1820.

73 Ibidem, 142-11497-1825.

74 Cuando el fiscal planteaba que Ford y Baudrix «no tienen mejor derecho» era en el sentido de lo que prescribía la ley de enfiteusis, pues sus campos no eran los que tenían los linderos más largos sobre el de Josefa Aguilar. 
es raro encontrar un expediente completo sobre un proceso judicial, como el que hemos presentado acerca de Comas, puesto que la mayoría se resolvían a partir de la negociación pactada entre las partes y no quedaron registradas estas prácticas políticas y jurídicas.

En el Estatuto provisional de 1815 se consideraba ciudadano a todos los hombres libres mayores o emancipados «siempre que haya nacido y resida en el territorio del Estado». También lo eran los extranjeros propietarios con residencia por más de cuatro años, correspondiéndole en este caso el sufragio activo. Se precisaba además que los extranjeros con más de diez años de residencia podrían tener voto pasivo y acceder a empleos de la «República». Estas normativas tenían estrecha relación con las soluciones jurídicas halladas en Cádiz y se correspondían con las tradiciones del Antiguo Régimen.

Sin embargo, las situaciones presentadas muestran que difícilmente pueden establecerse criterios abstractos para la resolución de los problemas políticos que afrontaron el Triunvirato y el Directorio en torno a los funcionarios extranjeros. Los casos analizados parecen indicar que las decisiones no fueron siempre uniformes: algunos optaron por alguna de las propuestas de la revolución, y otros por la continuidad de las prácticas del imperio o algunas formas más atenuadas de dependencia del mismo. No era posible, por consiguiente, que los «españoles europeos» adquirieran carta de ciudadanía del nuevo estado por requisitos normativos. Por otra parte, las panaderas de un recóndito pueblo de la pampa supieron adecuarse a los nuevos tiempos para resguardar sus intereses económicos, apelando a algunos de los enunciados más radicales de Buenos Aires, como los de Monteagudo que define la ciudadanía a partir de los derechos de nacimiento en el territorio -para él toda América-, pero que de manera ambigua eran reconocidos ya en el principio de naturaleza que hemos señalado.

Estos casos muestran que los derechos del natural y de vecino fueron los principales ejes sobre los que se continuaron planteando las prácticas políticas. En la ciudad de Buenos Aires, las cartas de ciudadanía se otorgaban discrecionalmente según lo resuelto por las autoridades y de acuerdo con las necesidades de la revolución. El caso de Comas y las panaderas presenta un ejemplo arquetípico de la pugna por los derechos de vecindad, disputados entre las partes y en el reconocimiento de las autoridades locales y superiores, que si bien reconocieron la utilidad de un ciudadano del oficio de Comas, gravaron sus ingresos, puesto que el catalán no pudo gozar de las exenciones de los vecinos del lugar. 


\section{BIBLIOGRAFÍA}

Alemano, María Eugenia, "Construcción de poder en la frontera: el caso del Sargento Mayor Diego Trillo", Mariana Canedo, Poderes intermedios en la frontera. Buenos Aires, siglos XVIII-XIX, Mar del Plata, EUDEM, 2013: 47-109.

Alemano, María Eugenia y Carlón, Florencia, "Prácticas defensivas, conflictos y autoridades en la frontera bonaerense. Los pagos de Magdalena y Pergamino (1752-1780)", Anuario del Instituto de Historia Argentina, 9 (La Plata, 2009): 15-42, http://www.anuarioiha.fahce.unlp.edu.ar/article/view/AHn09a02/pdf.

Álvarez Alonso, Clara, “Un Rey, una Ley, una Religión (Goticismo y Constitución histórica en el debate constitucional gaditano)", Revista Historia Constitucional, 1 (Oviedo, 2000), http://www.seminariomartinezmarina.com/ojs/index.php/historiaconstitucional/article/download/106/90.

Amaral, Samuel, "Del mercantilismo a la libertad: las consecuencias económicas de la independencia argentina", Leandro Prados de la Escosura y Samuel Amaral (eds.), La independencia americana: consecuencias económicas, Madrid, Alianza, 1993: 201-216.

Banzato, Guillermo, Ocupación y acceso a la propiedad legal de la tierra en la región nordeste del río Salado: Chascomús, Ranchos y Monte, 1780-1880, tesis de doctorado, Univeridad Nacional de La Plata, 2002, http://www.memoria.fahce.unlp. edu.ar/tesis/te.17/te.17.pdf.

Banzato, Guillermo, La expansión de la frontera bonaerense. Posesión y propiedad de la tierra en Chascomús, Ranchos y Monte, 1780-1880, Bernal, Universidad Nacional de Quilmes, 2005.

Banzato, Guillermo y Quinteros, Guillermo, "La ocupación de la tierra en la frontera bonaerense. El caso de Chascomús, 1779-1821”, Estudios/Investigaciones, 11 (La Plata, 1992): 37-76, http://www.memoria.fahce.unlp.edu.ar/libros/pm.197/pm. 197.pdf.

Bourin, Monique y Durand, Robert, "Forasteros y vecinos", Lester K. Little y Barbara H. Rosenwein, La Edad Media a debate, Madrid, Akal, 2001: 289-303.

Candioti, Magdalena, “Los jueces de la Revolución: pertenencia social, trayectorias políticas y saberes expertos de los encargados de hacer justicia en Buenos Aires (1810-1830)", Mónica Alabart, María Alejandra Fernández y Mariana A. Pérez, Buenos Aires, una sociedad que se transforma. Entre la colonia y la Revolución de Mayo, Buenos Aires, Prometeo-UNGS, 2012: 287-324.

Cansanello, Oreste Carlos, De súbditos a ciudadanos. Ensayo sobre las libertades en los orígenes republicanos. Buenos Aires, 1810-1852, Buenos Aires, Imago Mundi, 2003. 
Canter, Juan, "El año XII, las asambleas generales y la revolución del 8 de octubre", Ricardo Levene (dir.), Historia de la Nación Argentina, Buenos Aires, El Ateneo, vol. 5, Segunda Parte, cap. XII, 1962a: 379-476.

Canter, Juan, "La Asamblea General Constituyente", Ricardo Levene (dir.), Historia de la Nación Argentina, vol. 6, Buenos Aires, El Ateneo, 1962b, Primera Parte, cap. I: 9-201.

Carzolio, María Inés, "En los orígenes de la ciudadanía en Castilla. La identidad política del vecino durante los siglos XVI y XVII", Hispania, LXII/211 (Madrid, 2002): 637-691, http://hispania.revistas.csic.es/index.php/hispania/article/ view/ 262/264.

Chiaramonte, José Carlos, “Ciudadanía, soberanía y representación en la génesis del estado argentino (1810-1852)", Hilda Sábato (coord.), Ciudadanía política y formación de las naciones. Perspectivas históricas de América Latina, México, Fondo de Cultura Económica, 1999: 94-118.

Cutolo, Vicente Osvaldo, Nuevo diccionario biográfico argentino, 7 vols., Buenos Aires, Elche, 1968-1985.

Di Meglio, Gabriel, Viva el bajo pueblo!: La plebe urbana de Buenos Aires y la política entre la Revolución de Mayo y el rosismo, 1810-1829, Buenos Aires, Prometeo, 2006.

Di Meglio, Gabriel, "Patria”, Noemí Goldman (ed.), Lenguaje y revolución. Conceptos políticos clave en el Río de la Plata, 1780-1850, Buenos Aires, Prometeo, 2008: 115-130.

Domínguez Ortiz, Antonio, “La concesión de 'naturalezas para comerciar con Indias' durante el siglo XVII”, Revista de Indias, 76 (Madrid, 1959): 227-239.

Fernández Albaladejo, Pablo, Materia de España. Cultura política e identidad en la España Moderna, Madrid, Marcial Pons, 2007.

Fradkin, Raúl O. y Ratto, Silvia, “¿Qué hacer con los prisioneros españoles? La construcción del 'enemigo' y las formas de dejar de serlo. Buenos Aires, 18171819”, Darío Barriera (coord.), La justicia y las formas de la autoridad: organización política y justicias locales en territorios de frontera. El río de la Plata, Córdoba, Cuyo y Tucumán, siglos XVIII y XIX, Rosario, ISHIR CONICET-Red Columnaria, 2010: 45-82.

Galarza, Antonio, “¿Quiénes son las autoridades? Un análisis socioeconómico de las autoridades locales en un partido del sur de la campaña de Buenos Aires. Chascomús entre 1808 y 1821", Anuario del Instituto de Historia Argentina, 12 (La Plata, 2012): 81-110, http://www.anuarioiha.fahce.unlp.edu.ar/article/view/IHA$n 12 a 03 / p d f 3$.

Galarza, Antonio y Banzato, Guillermo, "Ejercer el poder en un pueblo de frontera. Juan Lorenzo Castro, hacendado, pulpero y alcalde de Chascomús (Buenos Aires) 
a inicios del siglo XIX", Prohistoria, 21 (Rosario, 2014): 105-129, http://www. scielo.org.ar/pdf/prohist/v21/v21a05.pdf.

Galmarini, Hugo Raúl, "La situación de los comerciantes españoles en Buenos Aires después de 1810”, Revista de Indias, 173 (Madrid, 1984): 273-290.

Galmarini, Hugo Raúl, "Los españoles de Buenos Aires después de la Revolución de Mayo: la suerte de una minoría desposeída del poder”, Revista de Indias, 178 (Madrid, 1986): 561-592.

Garavaglia, Juan Carlos, "La economía rural de la campaña de Buenos Aires vista a través de sus precios: 1756-1852”, Raúl Fradkin y Juan Carlos Garavaglia (ed.), En busca de un tiempo perdido. La economía de Buenos aires en el país de la abundancia, 1750-1865, Buenos Aires, Prometeo, 2004: 107-158.

Garavaglia, Juan Carlos, "Manifestaciones iniciales de la representación en el Río de la Plata: la Revolución en la laboriosa búsqueda de la autonomía del individuo", Juan Carlos Garavaglia, Construir el estado e inventar la nación. El Río de la Plata, siglos XVIII-XIX, Buenos Aires, Prometeo, 2007: 165-198.

Garavaglia, Juan Carlos, "Una breve nota acerca de los 'patriotas criollos' en el Río de la Plata”, Prohistoria, 12 (Rosario, 2009): 93-102, http://www.scielo.org.ar/pdf/ prohist/v12/v12a04.pdf.

González, Julio V., Filiación histórica del gobierno representativo, 2 vols., Buenos Aires, 1938.

Halperín Donghi, Tulio, Revolución y guerra: Formación de una élite dirigente en la Argentina criolla, Buenos Aires, Siglo XXI, 1972.

Herzog, Tamar, Vecinos y extranjeros. Hacerse español en la Edad Moderna, Madrid, Alianza, 2006.

Infesta, María Elena, La pampa criolla, Mar del Plata, EUDEM, 2007.

Lambré, Tomás (coord.), El redactor de la Asamblea del año XIII, Buenos Aires, Del nuevo Extremo, 2010.

León Matamoros, María Graciela, "El conflicto de los españoles ante el proceso de emancipación: Los casos del Río de La Plata y México en los albores del siglo XIX”, Anuario del Instituto de Historia Argentina, 10 (La Plata, 2010): 15-36, http://www.anuarioiha.fahce.unlp.edu.ar/article/view/AHn10a01/pdf.

Levene, Ricardo, "El Congreso General de las Provincias y la conferencia del 18 de diciembre", Ricardo Levene (dir.), Historia de la Nación Argentina, vol. 5, Buenos Aires, El Ateneo, 1962a, Segunda Parte, cap. VIII: 273-303.

Levene, Ricardo, "El 5 y 6 de abril de 1811 y sus consecuencias nacionales", Levene, Ricardo (dir.), Historia de la Nación Argentina, Buenos Aires, El Ateneo, t. 5, Segunda Parte, cap. X, 1962b: 323-347.

Monteagudo, Bernardo de, Horizontes politicos, La Plata, Terramar, 2008. 
Néspolo, Eugenia, “La 'Frontera' Bonaerense en el siglo XVIII un espacio políticamente concertado: fuertes, vecinos, milicias y autoridades civiles-militares", Mundo Agrario, 13 (La Plata, 2006), http://www.mundoagrario.unlp.edu.ar/articlel view/v07n13a08/1180.

Néspolo, Eugenia, Resistencia y complementariedad. Gobernar en Buenos Aires. Luján en el siglo XVIII. Un espacio políticamente concertado, Villa Rosa, Escaramujo, 2012.

Otero, José Pacífico, Estudio biográfico sobre Fray Cayetano José Rodríguez y recopilación de sus producciones literarias, s/l, Tipografía de F. Domenici, 1899, https://archive.org/details/estudiobiogrfic00otergoog.

Pérez Bustamante, Rogelio y Baró Pazos, Juan, El Gobierno y la Administración de los pueblos de Cantabria, 2 vols., Santander, Diputación Regional de Cantabria-Universidad de Cantabria, 1988.

Pérez, Mariana, "Un grupo caído en desgracia: los españoles europeos de Buenos Aires y la Revolución de Mayo", Entrepasados, 35 (Buenos Aires, 2009): 109127.

Pérez, Mariana, “¡Viva España y mueran los patricios! La conspiración de Álzaga de 1812”, Mónica Alabart, María Alejandra Fernández y Mariana A. Pérez, Buenos Aires, una sociedad que se transforma. Entre la colonia y la Revolución de Mayo, Buenos Aires, Prometeo-UNGS, 2012: 59-93.

Rey Castelao, Ofelia, "Los gallegos en el Río de la Plata durante la época colonial”, Xosé Manoel Núñez Seixas y Pilar Cagiao Vila (comps.), La Galicia austral: la inmigración gallega en la Argentina, Buenos Aires, Biblos, 2001: 23-51.

Salvatto, Fabricio Gabriel, "La gracia real bajo la forma republicana en el Rio de la Plata. Vecindad y naturaleza en el litoral rioplatense (1808-1824)", Diacronie. Studi di Storia Contemporanea, 16 (Bologna, 2013), http://www.studistorici.com/ wp-content/uploads/2013/12/11_SALVATTO.pdf.

Salvatto, Fabricio Gabriel, La equiparación entre los derechos de vecino y de natural en España, siglos XVII al XIX, Anuario digital, 26 (Rosario, 2014): 153-172, http://anuariodehistoria.unr.edu.ar/ojs/index.php/Anuario/article/view/156/164.

Salvatto, Fabricio Gabriel y Banzato, Guillermo, "Poderes locales y gobierno central ante el cambio de régimen en Buenos Aires: cartas de ciudadanía, cargos públicos y práctica de oficios, 1812-1815", VII Jornadas de Historia y Cultura de América, II Congreso Internacional y II Encuentro de Jóvenes Americanistas. La construcción de las independencias: documentos, actores y representaciones, Montevideo, Universidad de Montevideo, 25 y 26 de julio de 2013, http://www.memoria.fahce. unlp.edu.ar/trab_eventos/ev.2518/ev.2518.pdf.

Salvatto, Fabricio Gabriel y Carzolio, María Inés, "Naturaleza y ciudadanía en España Moderna. De la representación del súbdito a los albores de la ciudadanía con- 
temporánea (siglos XVII-XIX)", Almanak. Guarulhos, 2015: 658-691, http://www. almanack.unifesp.br/index.php/almanack/article/view/1138/pdf_1.

Urien, Carlos M., Soberana Asamblea General Constituyente de 1813, Buenos Aires, Maucci Hnos., 1913.

Fecha de recepción: 20 de febrero de 2014.

Fecha de envío de las modificaciones: 6 de enero de 2015.

Fecha de aceptación: 12 de enero de 2015.

\section{Naturales, vecinos and foreigners exercising public office and jobs Buenos Aires (city and countryside), 1812-1815}

In this article we analyse the legal and political status of foreigners in public office and exercising jobs in the Rio de la Plata between 1812 and 1815, from original documents of the period. We show that the rights of naturales and vecinos were the main lines along which political practices continued to be defined. In Buenos Aires, the granting of letters of citizenship by the authorities was discretionary and depended on the needs of the revolution.

KEY WORDS: jobs; public office; citizenship; May Revolution. 